\title{
BANNED FIXED DRUG COMBINATION: AN OVERVIEW
}

\author{
Akshata Shriyan* \\ 70/2H ground floor, 6th cross Janatha colony, Hulimavu Bannerghatta road \\ Bangalore, Karnataka - 560076, India.
}

\begin{abstract}
Combination of two or more active drugs in a single pharmaceutical dosage form is known as fixed drug dose combination. Irrational therapy results in Adverse Drug Reaction (ADR), emergence of resistant microorganisms, complications - confusing/ delaying the correct diagnosis and drug resistance. The health ministry banned the manufacturing, sales and distribution of 328 Fixed Dose Combinations (FDCs) of drugs $4^{\text {th }}$ august 2018 and restricted another six on $12^{\text {th }}$ September 2018. This ends a protracted legal battle between manufactures of these combination drugs and ministry, which has been working since 2016 to get these irrational and unsafe drugs banned. Among the roughly 6000 brands estimated to be affected by the ban are popular drugs like Painkiller Nicip D, Skin cream Pandre, Combination antidiabetic drug Gluconorm PG, Antibiotic Lupidiciox and Antibacterial Taxim AZ. The central government had prohibited 344 FDCs under section 26A of drug and cosmetics Act, 1940 on $10^{\text {th }}$ March 2016 and later added five more to the list. The supreme court on December $15^{\text {th }}$ 2017 asked for the matter to be examined by the Drug Technical Advisory Board (DTAB). They concluded in this report that there was no therapeutic justification for the ingredients and Kokate committee, which studied the irrationality of various FDCs, citied the rising "antibiotic resistance" in the country as one of the reasons.
\end{abstract}

Keywords: Irrational therapy, Fixed drug combination (FDCs), Therapeutic justification.

\section{INTRODUCTION}

\section{What is FDCs?}

A Combination of two or more active ingredients in a fixed ratio of doses, combined to form a single pharmaceutical dosage form is known as FDC.

USA defines a fixed dose combination product "as a product composed of any combination of a drug and device or a biological product and a device or a drug and a biological product or a drug, device and a biological product use for treatment" or In general, Fixed Dose (drug) Combination is defined as "a combination of two or more active pharmaceutical ingredients or compounds formulated as a single medicine irrespective of its dosage form designed".

\section{How was FDC termed?}

Here, the product is composed of two or more ingredients that are in a fixed composition ratio or particular dose, hence the term fixed ratio or dose combination is termed.

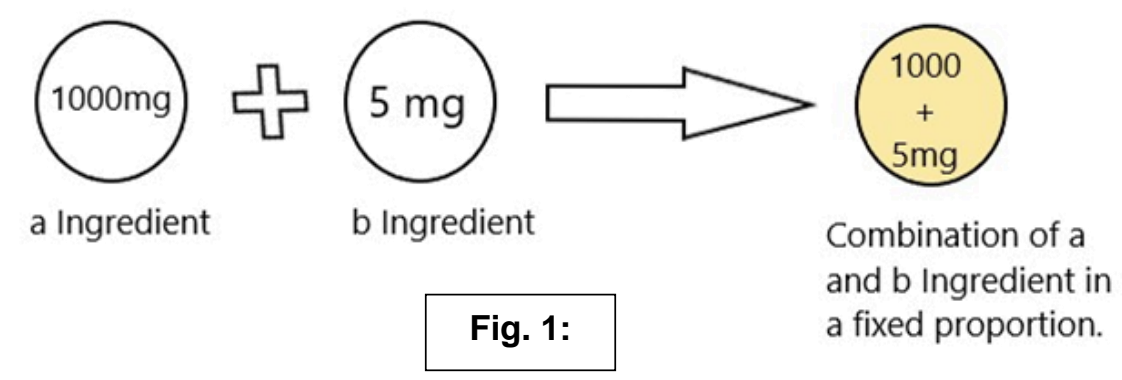


The two main rules of fixed drug composition are

1. The drugs to be combined should have approximately equal to plasma half-life

2. The ratio of doses of each component should depend on apparent Volume of Distribution (Vd) and plasma concentration.

\section{What makes them so popular?}

Simple answer is cost, instead of buying two or more medicines, a patient can just buy one FDC medicine to treat multiple illness symptoms.

Pharma companies, prefer to manufacture them because it is cheaper and quicker to combine existing active ingredients, to make new products than to discover new medicines and manufacture them separately.

\section{Why has the government banned them?}

The health ministry took this decision after the Drugs Technical Advisory Board recommended that "there is no therapeutic justification" for the ingredients contained in the banned FDC drugs and that these medicines "may involve risk to human beings".

\section{Why didn't the government crackdown on FDCs earlier?}

The health ministry was aiming for "irrational" and "unsafe" FDCs for over two years now. In March 2016, the government had banned 344 FDCs, adding five more to the list subsequently, following a report submitted by the Prof CK Kokate committee.

But drug manufacturers, such as Pfizer, Procter \& Gamble (P\&G), Abbott, Glenmark, Sanofi, Wockhardt, Cipla, Lupin and Dr Reddy's, had immediately moved to various courts against the decision. The Delhi High Court alone had received over 450 petitions seeking a stay on the ban.

In December 2016, the Delhi High Court squashed the Centre's decision, noting that it had acted on the advice of a 'technical committee', instead of consulting the Drugs Technical Advisory Board (DTAB) or the Drugs Consultative Committee. According to the bench, this violated the provisions of the Drugs and Cosmetics Act.

The health ministry had challenged this ruling in Supreme Court and, in December 2017, the latter directed DTAB to decide the fate of these FDCs.

Incidentally, the DTAB has recommended restricted manufacture and sale of six other FDCs, subject to certain conditions based on their therapeutic justification. The SC also ruled that the government could not use the DTAB report to prohibit 15 of the 344 drugs in the original list as these have been manufactured in India since before 1988.

According to The Times of India, this exception covers several popular cough syrups, painkillers and cold medication with sales amounting to over Rs 740 crore annually. However, the apex court told the ministry that it is free to initiate a fresh investigation into the safety of these 15 drugs if it wants them banned.

\section{ADVANTAGES}

- Combination of 2 or more drugs with different effect gives greater therapeutic effect.

- Public health, low Side effects - high efficacy

- FDC are more convenient to prescribed and consumed.

- Better patient compliance.

- Patient Adherence to the regimen is comparatively more in FDC.

- It is cheaper to purchase an FDC product than to purchase the products separately.

- FDC is very useful to treat disease like HIV, Tuberculosis, Malarial and many such which include multiple drug therapy.

- Lower risk to anti-microbial treatment and antimicrobial resistance.

\section{DISADVANTAGES}

- FDCs discourage separate titration of each active ingredient. This is a particular problem when both of the active ingredients require dose titration. Indeed, it can be argued that the very existence of an FDC discourages adjustment of doses to the patient's needs (if that is appropriate for the combination in question).

- When the active ingredients in question have different pharmacokinetics and/or pharmacodynamics, an FDC may not be appropriate.

- Unless both of the active ingredients are available as separate entities, FDCs encourage polypharmacy irrespective of whether it is appropriate for a particular patient.

- Health risk, side effects, drug interaction and ADRs

- FDCs are popular only because of profits. 


\section{OBJECTIVE}

- Reason for Ban on fixed drug combination drugs.

- Common Drugs that have been Banned

\section{EXPERIMENTAL METHODOLOGY}

An observational study and collection of data was done on the Banned 328 drugs, to study the common drugs that have been banned with the common Fixed drug combinations. The data was collected from various websites and articles (given the reference below).

Table 1: Review on common banned drugs

\begin{tabular}{|c|c|c|}
\hline $\begin{array}{c}\text { SI. } \\
\text { No. }\end{array}$ & Banned Drugs & No. of Drugs banned \\
\hline 1. & Aceclofenac & 4 \\
\hline 2. & Acetaminophen & 4 \\
\hline 3. & Amoxicillin & 5 \\
\hline 4. & Azithromycin & 6 \\
\hline 5. & Diclofenac & 14 \\
\hline 6. & Nimesulide & 15 \\
\hline 7. & Levocetirizine & 18 \\
\hline 8. & Cetirizine & 34 \\
\hline 9. & Paracetamol & 76 \\
\hline
\end{tabular}

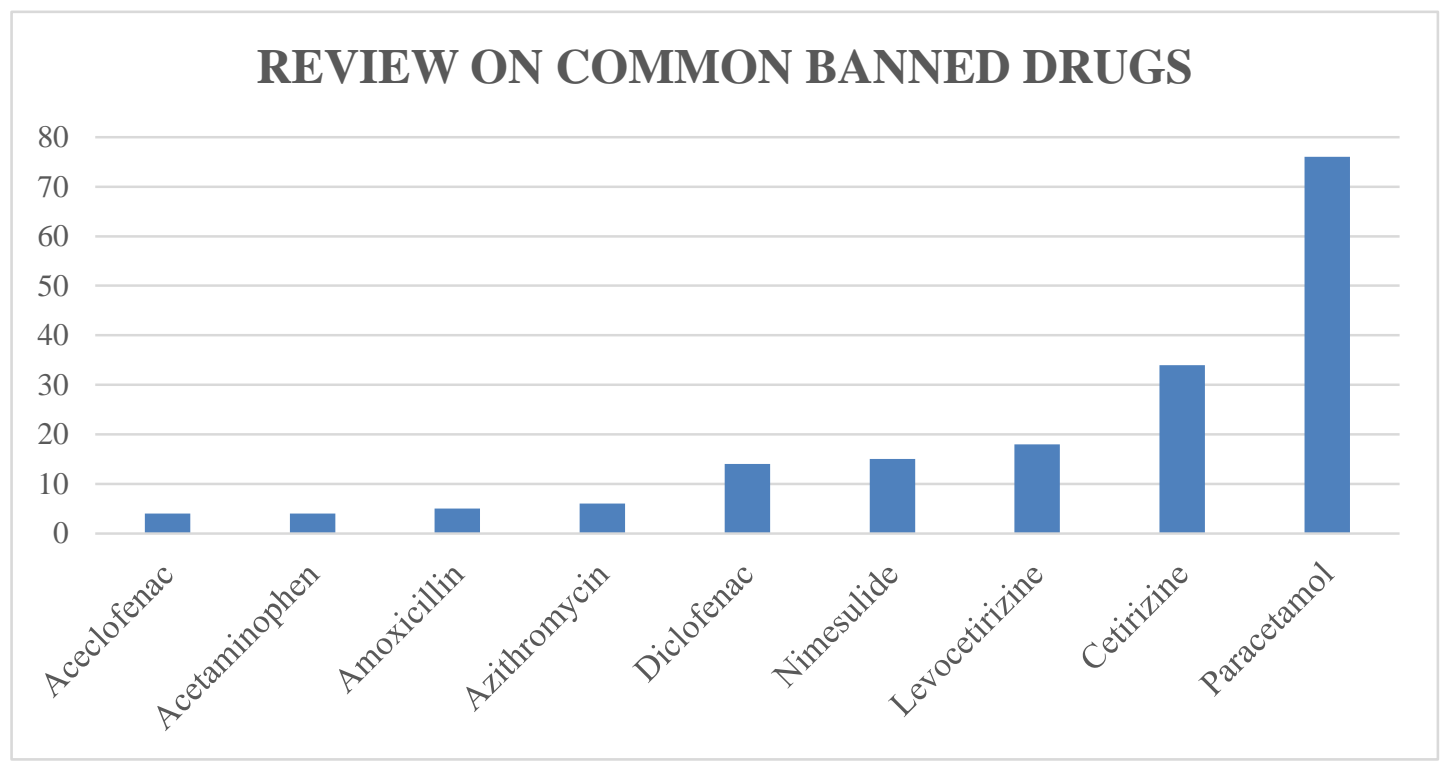

Fig. 2:

Review on common fixed drug combination

1. Cetirizine dihydrochliride + dextromethorphan hydrobromide and phenylephrine $\mathrm{Hcl}$
a. Brand Name: Galirex
b. Manufacturer: Leeford Health care limited

2. Nimesulide + Cetirizine + Phenylephrine + paracetamol + caffeine
c. Brand Name: Benacof
d. Manufacturer: Taj Pharmaceutical limited

3. Nimesulide + Diclofenac

e. Brand Name: Nicip D

f. Manufacturer: Cipla Limited

4. Nimesulide + Cetirizine + Caffeine

g. Brand Name: Medco Plus

h. Manufacturer: Pharmaceutical

Aegis

5. Paracetamol + Phenylephrine + Chlorpheniramine + Dextromethorphan + caffeine

i. Brand Name: Mulcotuf - P

j. Manufacturer: Zevion Healthcare 
6. Paracetamol + Cetirizine + Caffeine

k. Brand Name: Citaclor - $\mathrm{P}$

I. Manufacturer: TOSC international

7. Aceclofenac + Paracetamol + Rabeprazole

m. Brand Name: Ace Proxyvon

n. Manufacturer: Wockhardt Limited

8. codeine + chlorpheniramine + Alcohol

o. Brand Name: Corex

p. Manufacturer: Pfizer

9. Phenylephrine Hydrochloride + Caffeine Anhydroud + Paracetamol

q. Brand Name: Vicks Action 500

r. Manufacturer: $P \& G$

10. Cefixime + Azithromycin

s. Brand Name: Taxim AZ

t. Manufacturer: Alkem Laboratory Limited

11. Glimepiride + metformin + Pioglitazone

u. Brand Name: Gluconorm PG

v. Manufacturer: Lupin Limited

12. Clobetasol Propionate + Ofloxacin + Ornidazole + Terbinafine

w. Brand Name: Panderm

x. Manufacturer: Macleods Pharmaceutical private limited

13. Nimesulide + Paracetamol

y. Brand Name: Sumo

z. Manufacturer: Alkem Laboratory Limited

14. Terbutaline + Bromhexine + Guaiphenesin + Dextromethorphan

aa. Brand Name: Ascoril

bb. Manufacturer: Glenmarks

15. Paracetamol + Caffeine Phenylephrine

cc. Brand Name: D'cold

dd. Manufacturer:

Para

Pharmaceutical Limited

\section{CONCLUSION}

How was the pharma sector affected by this ban?

Large pharma companies said that the impact was expected to be negligible since, the FDCs are less than $2 \%$ of the pie. They added that over the last couple of years, they have either phased out such drugs or changed the combination.

Irrational therapy results in Adverse drug reaction, emergence of resistant microorganisms, financial complications costlier, masking/ confusing/ delaying the correct diagnosis.

paracetamol was considered the most common combinational drug that has been banned. This may be because of the frequent and common use of paracetamol as it is available as OTC drug.

Excessive use of paracetamol leads to Hepato - toxicity.

\section{REFERENCES}

1. Gautam C and Saha L. Fixed dose drug combinations (FDCs): rational or irrational: a view point. 2020.

2. [Internet]. 2020 [cited 22 August 2020]. Available from: http://apps.who.int/medicinedocs/en/d/ Js4955e/7.1.html\#Js4955e.7.1

3. Dissertation Report on Banned FDC drugs in India on 10th March [Internet]. Slideshare.net. 2020 [cited 22 August 2020]. Available from: https://www.slideshare.net/akshaysax ena2311/final-61671894

4. WEEK T, Week $T$ and dose A. A strong dose [Internet]. theweek.in. 2020 [cited 22 August 2020]. Available from:

https://www.theweek.in/theweek/busin ess/ban-on-suspect-drugs.html

5. Shaji $J$ and Lodha S. Regulatory Status of Banned Drugs in India [Internet]. ljper.org. 2010 [cited 22 August 2020]. Available from: http://www.ijper.org/sites/default/files/l JPER 44_1_12.pdf

6. Gupta $Y$ and Ramachandran S. Fixed dose drug combinations: Issues and challenges in India. Indian Journal of Pharmacology. 2016;48(4):347.

7. Saha K. Use of nimesulide in Indian children must be stopped. BMJ.2003; 326:713.

8. Office of Combination Products, Food and Drug Administration, USA: available from: URL: http://www.fda.gov/oc/combination/21 CFR Part 3.2(e).

9. Gautam CS and Aditya S. Irrational drug combinations: need to sensitize under graduate. Indian J Pharmacol. 2006;38(3):169-70.

10. Sharma Bora N. Banned Drugs in India: An Introspective Viewpoint. Acta Scientific Pharmaceutical Sciences. 2019;3(12):56-56.

11. Goswami N, Patel P, Dikshit R and Gandhi A. An evaluation of knowledge, attitude and practices about prescribing fixed dose combinations among resident doctors. Perspectives in Clinical Research. 2013;4(2):130.

12. McGettigan $P$, Roderick $P$, Mahajan $R$, Kadam $A$ and Pollock $A$. Use of Fixed Dose Combination (FDC) Drugs in India: Central Regulatory Approval and Sales of FDCs Containing NonSteroidal Anti-Inflammatory Drugs (NSAIDs), Metformin, or Psychotropic Drugs. PLOS Medicine. 2015;12(5):e1001826. 
13. Balat J, Gandhi A, Patel P and Dikshit R. A study of use of fixed dose combinations in Ahmedabad, India. Indian Journal of Pharmacology. 2014;46(5):503.

14. Avijit C. Fixed dose combinations in therapy- Express Pharma. India; Indian Express Newspapers Limited [updated 2007 August 15; cited 2008 February 25]. Available from: http://www.expresspharmaonline.com/ 20070815/research02.shtml.

15. Poudel A, Palaian S, Shankar P, Jayasekera $\mathrm{J}$ and Izham M. Irrational fixed dose combinations in Nepal: Need for intervention. Kathmandu University Medical Journal, 6(3), 399405.

https://doi.org/10.3126/kumj.v6i3.1723

16. Srinivasan S. Fixed Dose Combinations and their Ban Issues of Concern [Internet]. Jpac.in. 2020 [cited 22 August 2020]. Available from: http://www.jpac.in/journalmanagement /index.php/JPAC/article/view/26/24
17. Patel K, Patel $P$ and Sekar M. Major Pharmacy Practice Challenge for India:Irrational Fixed Dose Combinations. Indian Journal of Pharmacy Practice. 2018;11(2):62-63. Available from: https://ijopp.org/sites/default/files/InJP harPract-11-2-62_0.pdf

18. Saxena A. Ban of more than 300 FDC drugs on 10th March [Internet]. Slideshare.net. 2016 [cited 22 August 2020]. Available from: https://www.slideshare.net/akshaysax ena2311/new-microsoft-powerpointpresentation-61671938

19. Soans A. Banned Fixed Dose Combination Drugs in India - Gazette Notification [Internet]. Slideshare.net. 2016 [cited 22 August 2020]. Available from:

https://www.slideshare.net/anupsoans/ banned-fixed-dose-combination-drugsin-india-gazette-notification. 